\title{
MASSA DA AMOSTRA, SUBSTRATO E TEMPERATURA PARA TESTE DE GERMINAÇÃO DE SEMENTES DE Eucalyptus dunnii MAIDEN
}

\author{
SAMPLE MATTER AMOUNT, SUBSTRATE TYPE AND TEMPERATURE FOR SEED \\ GERMINATION TEST OF Eucalyptus dunnii MAIDEN
}

\author{
Ricardo Cetnarski Filho ${ }^{1}$ Ruy Inácio Neiva de Carvalho ${ }^{2}$
}

\section{RESUMO}

O objetivo do trabalho foi estabelecer a massa da amostra, o tipo de substrato e a temperatura mais adequados à realização de teste de germinação de sementes de Eucalyptus dunnii em laboratório. As sementes foram adquiridas da empresa Klabin Paraná Papéis, provenientes do município de Telêmaco Borba, PR. O trabalho se constituiu de dois experimentos realizados no Laboratório de Técnica de Sementes da Pontifícia Universidade Católica do Paraná. O primeiro experimento foi realizado para determinação da massa ideal da amostra para o teste de germinação utilizando-se cinco tratamentos representados por diferentes massas de amostras do lote $(365,730,1.095,1.460$ e $1.825 \mathrm{mg})$, correspondentes a 50, 100, 150, 200 e $250 \mathrm{mg}$ de sementes puras, com quatro repetições. Após 14 dias foi avaliado o número de sementes germinadas por grama de amostra. No segundo experimento, foi verificada a influência dos substratos papel, areia e vermiculita e das temperaturas de 20,25 e $30^{\circ} \mathrm{C}$ na germinação das sementes. Foram analisadas as variáveis germinação (\%), tempo médio de germinação (dia), velocidade média de germinação $\left(\right.$ dia $\left.^{-1}\right)$, índice de velocidade de germinação e entropia (bits). Concluiu-se que o teste de germinação de sementes de Eucalyptus dunnii pode ser realizado com massa equivalente a $50 \mathrm{mg}$ de sementes puras. Os substratos areia ou papel devem ser utilizados e a temperatura de $20^{\circ} \mathrm{C}$ proporcionou melhor desempenho da população de sementes de Eucalyptus dunni no teste de germinação.

Palavras-chave: Eucalipto; fisiologia; análise de sementes.

\section{ABSTRACT}

The objective of this work was to set the adequate amount of sample matter, the substrate type and the ideal temperature to perform the germination test of Eucalyptus dunnii in laboratory. Seeds, from Telêmaco Borba, PR, were purchased at Klabin Paraná Papéis. Two experiments were performed in the Seed Improvement Laboratory of the Pontific Catholic University of Parana (PUCPR). The first experiment was performed to determine the ideal amount of sample matter for the germination test. It had five treatments and four replications. The five treatments were different sample matters $(365,730,1.095,1.460$ and $1.825 \mathrm{mg})$ from the lot, which corresponded to 50,100,150, 200 and $250 \mathrm{mg}$ of pure seeds. The number of germinated seeds per gram of the samples was evaluated after 14 days. In the second experiment, the influence of paper, sand and vermiculite substrates and temperature $\left(20,25\right.$ or $\left.30^{\circ} \mathrm{C}\right)$ on seed germination was verified. Percent germination (\%), average germination time (days), average germination speed $\left(\right.$ day $\left.^{-1}\right)$, index of germination speed and entropy (bits) were analyzed. It was concluded that seed germination of Eucalyptus dunnii may be performed with sample matter equivalent to $50 \mathrm{mg}$ of pure seeds. Sand or paper must be used for the germination test. A better performance of the Eucalyptus dunni seed population was observed at $20^{\circ} \mathrm{C}$.

Keywords: Eucalyptus; physiology; seed analysis.

\section{INTRODUÇÃO}

O Eucalyptus dunnii Maiden é originário da Austrália e é amplamente cultivado no Brasil, especialmente nas regiões do planalto Catarinense e Paranaense, por apresentar rápido crescimento, rusticidade e tolerar muito bem o frio (LORENZI, 2003). Assim como na Região Sul do Brasil, as florestas plantadas na região Sudeste visam garantir o suprimento de matéria-prima para as indústrias de papel e celulose, siderurgia a carvão vegetal, lenha, serrados, compensados, lâminas e painéis reconstituídos (EMBRAPA, 2006). Até o final de 2004 o cultivo do eucalipto correspondia a $74 \%$ do total da área

1. Engenheiro Agrônomo, MSc., Autônomo, Rua Joinvile, 2777, CEP: 83020-000, São José dos Pinhais (PR). ricardotche@hotmail.com

2. Engenheiro Agrônomo, Dr., Professor Titular do Centro de Ciências Agrárias e Ambientais, Pontifícia Universidade Católica do Paraná, BR 376, km 14, Bairro Costeira, CEP: 80010-500, São José dos Pinhais (PR). da PUCPR. Bolsista de Produtividade em Pesquisa, nível II - CNPq. ruy.carvalho@pucpr.br 
comercial reflorestada no Brasil. Em São Paulo, o cultivo do eucalipto corresponde a mais de $90 \%$ da área de reflorestamento no estado (BRACELPA, 2006).

Das folhas do eucalipto, extraem-se óleos essenciais empregados em perfumes, remédios e produtos alimentícios e de limpeza. A casca oferece tanino, usado no curtimento do couro e o tronco fornece madeira para sarrafos, lambris, ripas, postes, mastros para barco, tábuas para embalagens e móveis. Sua fibra é utilizada como matéria-prima para a fabricação de papel e celulose (AMBIENTE BRASIL, 2006).

A propagação do eucalipto pode ser feita por sementes ou por estaquia, com destaque à miniestaquia de ramos obtidos em jardins miniclonais (FERREIRA et al., 2004) e microestaquia de jardins microclonais (TITON et al., 2002). A propagação por sementes é viável e utilizada comercialmente, mas por causa das suas pequenas dimensões o seu manejo despende cuidado e tempo adicional. Da mesma forma, o exame da qualidade das sementes em laboratório é dificultado e condutas específicas devem ser constituídas para a normatização dos processos laboratoriais. As Regras para Análise de Sementes (RAS) (BRASIL, 1992) trazem a descrição de normas para 47 espécies do gênero Eucalyptus, mas não há citação do Eucalyptus dunnii. A massa da amostra recomendada pela RAS para o teste de germinação de sementes de eucalipto varia de 0,1 a 1,0 g (BRASIL, 1992). Porém, Oliveira et al. (1996) sugeriram que o tamanho mínimo da amostra de trabalho de sementes das espécies do gênero Eucalyptus seja reduzido, pois em exames em laboratório o tempo gasto para testes com essas espécies, em conformidade com a prescrição da RAS, é muito longo.

Para 38 espécies de Eucalyptus citadas na RAS, as temperaturas indicadas para germinação variam de 20 a $30^{\circ} \mathrm{C}$, mas há indicações de temperaturas desde $15^{\circ} \mathrm{C}$ (Eucalyptus elata, Eucalyptus fastigiata, Eucalyptus macrorrynchaI, Eucalyptus muelleriana, Eucalyptus pauciflora, Eucalyptus polybractea e Eucalyptus regnans) até $35^{\circ} \mathrm{C}$ (Eucalyptus deglupta, Eucalyptus largiflorens e Eucalyptus rudis) demonstrando que esse fator é muito variável de acordo com a espécie analisada (BRASIL, 1992).

A resposta da germinação em relação à temperatura depende da espécie, variedade, região de origem e tempo de armazenamento, porém seu efeito na germinação pode ser expresso em temperaturas mínimas, ótimas e máximas nas quais a germinação pode ocorrer. A faixa de temperatura ótima é aquela que permite a maior porcentagem de germinação no menor espaço de tempo (CARVALHO e NAKAGAWA, 1988).

Além da temperatura, o substrato utilizado também influencia a condução do teste de germinação. Dentre os fatores envolvidos na escolha do material a ser utilizado como substrato estão a sua composição, capacidade de retenção de água, porosidade, pureza, acidez, resistência e textura (BRASIL, 1992).

Oliveira et al. (1996), reunindo informações sobre testes de germinação de sementes florestais durante seis anos em diversos laboratórios e trabalhos de pesquisa, indicaram que os substratos mais utilizados para análises de germinação são: papel filtro (28\%); papel toalha $(20,5 \%)$; areia (19\%); vermiculita (19\%); terra (5\%); papel mata-borrão (5\%); carvão $(2,5 \%)$ e outros $(1 \%)$. Os autores citaram que bons resultados foram obtidos utilizando-se a vermiculita como substrato e fazem a sugestão desta ser prescrita pela RAS. Pina-Rodrigues et al. (2004) destacaram a vermiculita e a areia como substratos que minimizam a ação de fungos do ambiente durante os testes de germinação. A vermiculita e a areia são substratos alternativos que já foram avaliados para outras espécies como a canela (Ocotea corymbosa (Meissn.) Mez) (BILIA et al., 1998) e a itaubarana [Acosmuim nitens (Vog.) Yakovlev] (VARELA et al., 2005). A vermiculita é comumente utilizada como substrato para propagação de plantas, pois possui alta capacidade de retenção de água, boa aeração e alto poder tampão (KÄMPF, 2000).

O objetivo deste trabalho é estabelecer a massa da amostra, o tipo de substrato e a temperatura mais adequados à realização de testes de germinação de sementes de Eucalyptus dunnii em laboratório.

\section{MATERIAL E MÉTODO}

O trabalho se constituiu de dois experimentos realizados no Laboratório de Técnica de Sementes da Pontifícia Universidade Católica do Paraná, localizado no município de São José dos Pinhais, PR. As sementes de Eucalyptus dunnii foram adquiridas da empresa Klabin Paraná Papéis, lote n. 3142, safra de 2006, provenientes do município de Telêmaco Borba, PR, localizado a uma altitude de $850 \mathrm{~m}$, latitude de $24^{\circ} 14^{\prime}$ Sul e longitude de 50 $35^{\prime}$ ' Oeste. De acordo com o Laudo n. 02/2006 do Laboratório de Análise de Sementes da Fundação de Pesquisas Florestais do Paraná - FUPEF da Universidade Federal do Paraná UFPR, as sementes do lote em questão possuíam $13,7 \%$ de sementes puras. 


\section{Determinação da massa da amostra}

Este experimento foi realizado em caixas gerbox com uma folha de papel para geminação umedecida com $8 \mathrm{~mL}$ de água deionizada no início do teste e mais $2 \mathrm{~mL}$ no sétimo dia. A tampa do gerbox foi umedecida com $1 \mathrm{~mL}$ de água na instalação do experimento. As caixas gerbox e pinças de ponta fina utilizadas nos testes receberam assepsia com álcool a 70\%. O teste de germinação foi realizado em germinador de câmara (BRASIL, 1992) modelo Mangersdorfii com temperatura de $25^{\circ} \mathrm{C}$. Os tratamentos foram representados por cinco diferentes massas de amostras do lote, com quatro repetições. De acordo com o percentual de sementes puras citado no lote, foram calculadas as cinco massas utilizadas (Tabela 1).

A avaliação foi realizada aos 14 dias após a instalação do teste, como sugerem as regras para análise de sementes para a maioria das espécies do gênero Eucalyptus (BRASIL, 1992), com a contagem do número total de plântulas normais em cada gerbox, sendo que o critério de germinação foi a protrusão visível da radícula a olho nu. Calculou-se o número de sementes germinadas por unidade de peso (plântulas por grama da amostra de trabalho) (PINÃ-RODRIGUES et al., 2004).

O delineamento experimental adotado foi o inteiramente casualizado com cinco tratamentos e quatro repetições. As médias dos tratamentos com diferenças significativas pelo teste $\mathrm{F}$ na análise de variância foram submetidas à análise de regressão.

TABELA 1: Massa de amostras de sementes de Eucalyptus dunnii e sua respectiva massa de sementes puras.

TABLE 1: Mass of seed sample of Eucalyptus dunnii and the respective mass of pure seeds.

\begin{tabular}{c|c|c}
\hline Tratamento & $\begin{array}{c}\text { Massa de sementes retirada da amostra } \\
\text { de trabalho }(\mathrm{mg})\end{array}$ & $\begin{array}{c}\text { Massa correspondente de sementes } \\
\text { puras }(\mathrm{mg})^{1}\end{array}$ \\
\hline T1 & 365 & 50 \\
T2 & 730 & 100 \\
T3 & 1.095 & 150 \\
T4 & 1.460 & 200 \\
T5 & 1.825 & 250 \\
\hline
\end{tabular}

Em que: ${ }^{1}$ de acordo com o laudo de análise de pureza (sementes puras $=13,7 \%$ ).

\section{Determinação da temperatura e substrato}

No segundo experimento, foi verificada a influência dos substratos papel, areia e vermiculita e das temperaturas de 20,25 e $30^{\circ} \mathrm{C}$ na germinação de sementes de Eucalyptus dunnii. O teste de germinação foi realizado como no primeiro experimento e foi utilizada a massa de $365 \mathrm{mg}$ de sementes da amostra de trabalho (correspondente a $50 \mathrm{mg}$ de sementes puras) em virtude do resultado do primeiro experimento. $\mathrm{O}$ número médio de sementes em cada amostra de $365 \mathrm{mg}$ foi de 117 sementes ( $\mathrm{cv}=5,1 \%)$ calculado utilizando-se quatro repetições.

O substrato papel constituiu-se no uso de uma folha de papel próprio para germinação de acordo com as exigências da RAS (BRASIL, 1992) umedecido com $7 \mathrm{~mL}$ de água deionizada. Para o substrato vermiculita, foram acondicionados $7 \mathrm{~g}$ de vermiculita de granulometria fina da marca Terra Mater ${ }^{\circledR}$ por caixa gerbox umedecida com $30 \mathrm{~mL}$ de água deionizada. Para o substrato areia, foram utilizados $80 \mathrm{~g}$ de Sand White Quartz Sigma ${ }^{\circledR}$ umedecida com $20 \mathrm{~mL}$ de água deionizada. O volume de água utilizado para umedecimento de cada substrato foi calculado previamente de acordo com a máxima capacidade de retenção de água do substrato analisado.

As avaliações foram realizadas no $2^{\circ}, 4^{\circ}, 6^{\circ}, 8^{\circ}$ e $10^{\circ}$ dias após o início dos testes, com a contagem do número total de plântulas em cada gerbox adotando-se como critério de germinação a protrusão visível da radícula. Com os dados obtidos, calcularam-se as seguintes variáveis:

- Porcentagem de germinação $(\mathrm{G})$ : calculada pela fórmula $\mathrm{G}=(\mathrm{N} / \mathrm{A})$ x 100 , em que: $\mathrm{N}=$ número de sementes germinadas; $\mathrm{A}=$ número de sementes na amostra $(\mathrm{A}=117)$. Unidade: \%.

- Índice de velocidade de germinação (IVG): calculado pela fórmula IVG $=\sum\left(n_{i} / t_{i}\right)$, em que: $n_{i}=$ número de sementes que germinaram no tempo "i"; $t_{i}=$ tempo após instalação do teste; $i=2 \rightarrow 10$ dias. Unidade: adimensional.

- Tempo médio de germinação (TMG): calculado pela fórmula TMG $=\left(\sum \mathrm{n}_{\mathrm{i}} \mathrm{t}_{\mathrm{i}}\right) / \sum \mathrm{n}_{\mathrm{i}}$, onde: $\mathrm{n}_{\mathrm{i}}=$ 
número de sementes germinadas por dia; $t_{i}=$ tempo de incubação; $i=2 \rightarrow 10$ dias. Unidade: dias.

- Velocidade média de germinação $(\mathrm{VMG})$ : calculada pela fórmula $\mathrm{VMG}=1 / \mathrm{t}$ onde: $\mathrm{t}=$ tempo médio de germinação. Unidade: dias ${ }^{-1}$.

- Entropia (E): realizada de acordo com procedimentos estatísticos adotados por Nassif e Perez (2000). Unidade: Bits.

O delineamento experimental adotado foi o inteiramente casualizado em um esquema fatorial $3 \times 3$, sendo um fator representado pelas temperaturas e outro pelos substratos utilizados, totalizando nove tratamentos com três repetições. As médias dos tratamentos com diferenças significativas pelo teste $\mathrm{F}$ na análise de variância foram comparadas pelo teste Tukey ao nível de $5 \%$ de probabilidade para o fator substrato e pela análise de regressão para o fator temperatura.

\section{RESULTADOS E DISCUSSÃO}

\section{Massa da amostra para teste de germinação}

As diferentes massas de sementes utilizadas para os testes de germinação no primeiro experimento não interferiram na germinação total ao final da avaliação, atingindo valores médios de 261 plântulas por grama de amostra de trabalho, sem diferença significativa entre os tratamentos (Prob. $>\mathrm{F}=0,5794$; $\mathrm{CV}=$ 17,4\%). Considerando-se o número calculado de 117 sementes por amostra de $365 \mathrm{mg}$ extrapolou-se o dado para 321 sementes por grama de amostra, fato que resulta num percentual médio de germinação de $81 \%$. Além de não interferir no resultado final, a redução da massa da amostra para análise de sementes de Eucalyptus dunnii facilitou a execução do teste pela melhor visualização das sementes. Portanto, o teste de germinação pode ser feito com amostras contendo $50 \mathrm{mg}$ de sementes puras.

\section{Temperatura e substrato para germinação}

No segundo experimento, realizado com amostras de $365 \mathrm{mg}$ (50 $\mathrm{mg}$ de sementes puras) em decorrência do resultado do primeiro experimento, a germinação média obtida à temperatura de $20^{\circ} \mathrm{C}$ foi de $91 \%$ mas, com o aumento da temperatura até $30^{\circ} \mathrm{C}$, ocorreu o decréscimo linear até $80 \%$ (Figura 1). Não houve interação significativa entre temperaturas e substratos, evidenciando que a queda na porcentagem de germinação com o aumento de temperatura ocorreu igualmente nos três substratos utilizados. A RAS (BRASIL, 1992) indica, para testes de germinação de sementes de outras espécies de Eucalyptus, temperaturas que variam de $15^{\circ} \mathrm{C}$ (Eucalyptus elata) a $35^{\circ} \mathrm{C}$ (Eucalyptus rudis). A temperatura de $20^{\circ} \mathrm{C}$ é recomendada para $28 \%$ das espécies de Eucalyptus citadas na RAS, como o Eucalyptus robusta. Para a maior parte das espécies (40\%), a temperatura de $25^{\circ} \mathrm{C}$ é recomendada, como para Eucalyptus viminalis e Eucalyptus citriodora. A temperatura de $30^{\circ} \mathrm{C}$ é sugerida para apenas $11 \%$ das espécies, como para Eucalyptus camaldulensis.

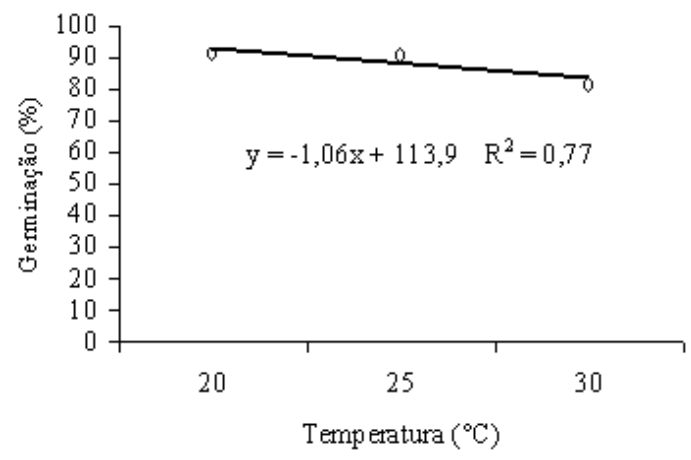

FIGURA 1: Germinação (\%) de sementes de Eucalyptus dunnii submetidas a diferentes temperaturas.

FIGURE 1: Germination (\%) of Eucalyptus dunnii seeds submitted to different temperatures.

Normalmente, a temperatura para germinação de sementes de espécies diversas varia entre 15 a $40^{\circ} \mathrm{C}$, com variações de acordo com a origem da semente em estudo. A faixa de temperatura ideal para germinação de sementes de aroeira (Myracrodruon urundeuva Allemão) é de 20 a $30^{\circ} \mathrm{C}$ (SILVA et al., 2002) e para sementes de tamareira (Phoenix roebelenii O'Brian) é de 25 a $30^{\circ} \mathrm{C}$ (IOSSI et al., 2003). Já para espécies oriundas da floresta tropical, como a samaumeira (Ceiba pentandra (Linn.) Gaertn.), a faixa ótima 
de temperatura é de 25 a $35^{\circ} \mathrm{C}$ (SOUSA et al., 2000), enquanto para a jabuticabeira (Myrciaria spp.) de regiões subtropicias, a temperatura ideal está entre 15 e $20^{\circ} \mathrm{C}$ (ANDRADE e MARTINS, 2003). A resistência ao frio do Eucalyptus (LORENZI, 2003) sugere que temperaturas amenas sejam mais adequadas à germinação de suas sementes e que elevações da temperatura podem prejudicar a expressão do máximo potencial de germinação. Pela análise da Figura 1, sugere-se a temperatura de $20^{\circ} \mathrm{C}$ para a realização do teste de germinação embora, pela relação linear encontrada, a extrapolação de dados à esquerda da reta sugira que a germinação seria maior a temperaturas mais baixas, podendo atingir $98 \%$ a $15^{\circ} \mathrm{C}$. Porém, a extrapolação de dados estatísticos em processos fisiológicos deve ser feita com cautela.

O tempo médio de germinação (TMG) na temperatura de $25^{\circ} \mathrm{C}$ foi de 4,63 dias e não foi influenciado pelos diferentes substratos. Nas temperaturas de 20 e $30^{\circ} \mathrm{C}$ o TMG de 5,39 e 4,58 dias respectivamente obtido no substrato areia foi menor que o encontrado na vermiculita (Tabela 2). Em associação ao maior percentual de germinação, a agilidade do teste é um fator favorável à análise de sementes (CARVALHO e NAKAGAWA, 1988). Somente no substrato areia a resposta do TMG em relação ao aumento de temperatura foi linear e decrescente, demonstrando ser um substrato fisicamente mais homogêneo em diferentes temperaturas (Figura 2). A germinação na areia a $30^{\circ} \mathrm{C}$ foi mais baixa $(80 \%)$, mas foi mais rápida. Porém, o ganho de tempo de menos de um dia é um benefício que não justifica a perda de mais de $10 \%$ de sementes germinadas. Nos substratos papel e vermiculita, a resposta do TMG não foi linear como na areia, representando substratos que apresentam alguma interferência no processo fisiológico normal de germinação e, em especial em temperaturas mais elevadas até $30^{\circ} \mathrm{C}$, podem ser fontes de interferências externas, que são indesejáveis aos testes (PINÃ-RODRIGUES et al., 2004).

TABELA 2: Tempo médio de germinação (dias) de sementes de Eucalyptus dunnii submetidas a diferentes temperaturas em diferentes substratos.

TABLE 2: Average time to germination (days) of Eucalyptus dunnii seeds submitted to different temperatures on several substrates.

\begin{tabular}{l|c|c|c}
\hline \multirow{2}{*}{ Substrato } & \multicolumn{4}{c}{ Temperatura $\left({ }^{\circ} \mathrm{C}\right)$} \\
\cline { 2 - 4 } & 20 & 25 & 30 \\
\hline Areia & $5,39 \mathrm{~b}$ & $4,48 \mathrm{~A}$ & $4,58 \mathrm{c}$ \\
Papel & $5,73 \mathrm{ab}$ & $4,62 \mathrm{~A}$ & $6,13 \mathrm{a}$ \\
Vermiculita & $6,13 \mathrm{a}$ & $4,79 \mathrm{~A}$ & $5,32 \mathrm{~b}$ \\
\hline Média & 5,75 & 4,63 & 5,34 \\
\hline CV $=6,2 \%$ & &
\end{tabular}

Em que: Médias seguidas por letras distintas na coluna diferem entre si ao nível de 5\% de significância.

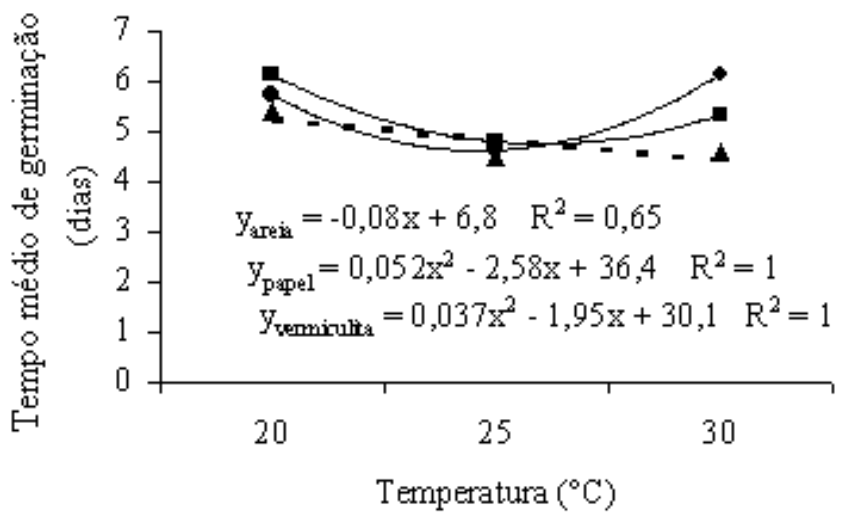

- Papel a Vermiculita A Areia

FIGURA 2: Tempo médio de germinação (dia) de sementes de Eucalyptus dunnii submetidas a diferentes temperaturas em diferentes substratos.

FIGURE 2: Average time to germination (day) of Eucalyptus dunnii seeds submitted to different temperatures on several substrates. 
A velocidade média de germinação (VMG) nas temperaturas de 20 e $25^{\circ} \mathrm{C}$ foi de 0,17 e 0,22 dia $^{-1}$ respectivamente e não foi influenciada pelo substrato utilizado. Na temperatura de $30^{\circ} \mathrm{C}$ o substrato areia apresentou VMG de $0,22 \mathrm{dia}^{-1}$ e foi superior aos substratos papel e vermiculita (Tabela 3 ). Somente no substrato areia, a resposta da VMG em função do aumento da temperatura foi linear, assim como para o TMG, porém crescente, evidenciando a maior homogeneidade de condições para germinação fornecidas pela areia em diferentes temperaturas (Figura 3). Nos substratos papel e vermiculita, a dinâmica não linear do TMG e da VMG em função do aumento da temperatura indicou que alguma característica física destes como a porosidade ou a retenção e distribuição da água, associada à elevada temperatura, pode ter sido inadequada para a germinação, retardando seu processo e impedindo a semente de expressar seu máximo potencial. Carvalho e Nakagawa (1988) citaram que a temperatura ótima para porcentagem de germinação é diferente da ótima para velocidade de germinação, sendo mais elevada para essa última. De fato, a germinação nos três substratos foi superior a $20^{\circ} \mathrm{C}$, porém a maior $\mathrm{VMG}$ ocorreu a $25^{\circ} \mathrm{C}$ para os substratos papel e vermiculita.

TABELA 3: Velocidade média de germinação $\left(\operatorname{dia}^{-1}\right)$ de sementes de Eucalyptus dunnii submetidas a diferentes temperaturas em diferentes substratos.

TABLE 3: Average speed of germination $\left(\right.$ day $\left.^{-1}\right)$ of Eucalyptus dunnii seeds submitted to different temperatures on several substrates.

\begin{tabular}{l|c|c|c}
\hline \multirow{2}{*}{ Substrato } & \multicolumn{4}{c}{ Temperatura $\left({ }^{\circ} \mathrm{C}\right)$} & 30 \\
\cline { 2 - 4 } & 20 & 25 & $0,22 \mathrm{a}$ \\
Areia & 0,18 a & $0,22 \mathrm{~A}$ & $0,19 \mathrm{~b}$ \\
Papel & $0,18 \mathrm{a}$ & $0,22 \mathrm{~A}$ & $0,16 \mathrm{~b}$ \\
Vermiculita & $0,16 \mathrm{a}$ & $0,21 \mathrm{~A}$ & 0,19 \\
\hline Média & 0,17 & 0,22 &
\end{tabular}

Em que: Médias seguidas por letras distintas na coluna diferem entre si ao nível de 5\% de significância.

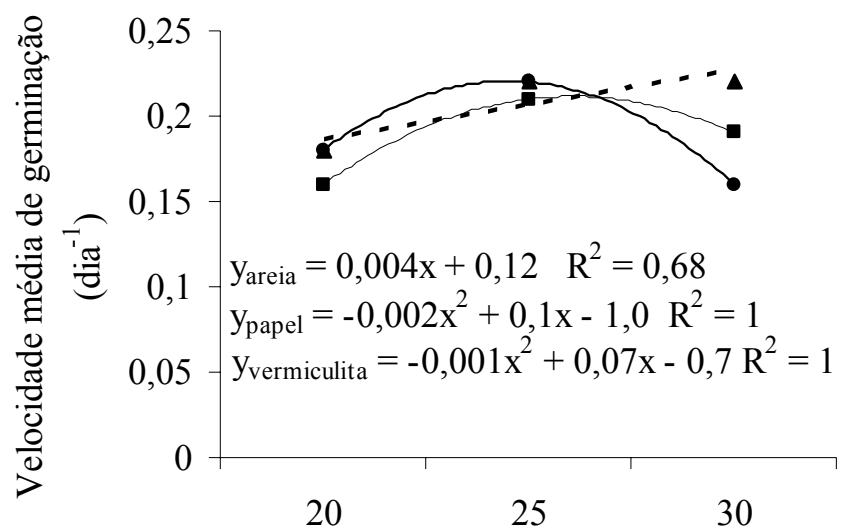

Temperatura $\left({ }^{\circ} \mathrm{C}\right)$

- Papel - Vermiculita $\Delta$ Areia

FIGURA 3: Velocidade média de germinação $\left(\mathrm{dia}^{-1}\right)$ de sementes de Eucalyptus dunnii submetidas a diferentes temperaturas em diferentes substratos.

FIGURE 3: Average speed of germination $\left(\right.$ day $\left.^{-1}\right)$ of Eucalyptus dunnii seeds submitted to different temperatures on several substrates.

Embora Pinã-Rodrigues et al. (2004) tenham relatado que a areia não é muito utilizada para análise de sementes florestais, a resposta linear obtida do TMG e VMG na areia (Figura 2 e 3) mostrou que esse substrato foi o que melhor atendeu à fisiologia de germinação das sementes de Eucalyptus dunnii. Da mesma forma, Oliveira et al. (1996) sugeriram que a vermiculita fosse incluída como substrato pela RAS, porém, para Eucalyptus dunnii, esta não demonstrou ser um bom substrato, pois sua textura e coloração dificultaram as avaliações em virtude da cor e das pequenas dimensões das sementes avaliadas. Pinã-Rodrigues et al. (2004) citaram que a vermiculita tem sido o substrato mais empregado em espécies florestais, porém 
recomendaram a vermiculita para testes de germinação de sementes de tamanho médio a grande e o papelfiltro para sementes pequenas. Para Pacheco et al. (2006) o substrato vermiculita e pó de coco permitiram bom desempenho germinativo de Myracroduon urundeuva Fr. All.. Machado et al. (2002) citaram que os substratos areia e papel são promissores para uso no teste de germinação em sementes de Tabebuia serratifolia (Vahl) Nicholson.

O índice de velocidade de germinação (IVG) das sementes de Eucalyptus dunnii foi superior nos substratos areia e papel, com valores de 27,54 e 22,40 respectivamente. A semelhança estatística do IVG no papel e na vermiculita $(20,30)$ demonstrou a ação mais favorável do substrato areia à germinação (Tabela 4). A resposta do IVG em relação ao acréscimo de temperatura seguiu um modelo quadrático com o ponto de máximo IVG a $25^{\circ} \mathrm{C}$, sugerindo essa temperatura como ideal para a germinação mais rápida (Figura 4). Não houve interação significativa entre substratos e temperaturas para o IVG.

TABELA 4: Índice de velocidade de germinação (IVG) de sementes de Eucalyptus dunnii em diferentes substratos.

TABLE 4: Germination speed index (IVG) of Eucalyptus dunnii seeds on several substrates.

\begin{tabular}{l|l}
\hline Substrato & \multicolumn{1}{|c}{ IVG } \\
\hline Areia & $27,54 \mathrm{~A}$ \\
Papel & $22,40 \mathrm{Ab}$ \\
Vermiculita & $20,30 \mathrm{~B}$ \\
\hline Média & 23,41 \\
\hline $\mathrm{CV}=20,3 \%$ & \\
\hline
\end{tabular}

Em que: Medias seguidas por letras distintas na coluna diferem entre si ao nível de 5\% de significância.

A entropia do sistema no teste de germinação não foi influenciada pelos diferentes substratos, mas sofreu acréscimo linear de acordo com o aumento da temperatura (Figura 5). A entropia do sistema mede sua organização, assim quanto menor a entropia do teste maiores são a organização e a sincronia da germinação das sementes contidas na amostra analisada. Assim, a maior sincronia de germinação ocorreu na temperatura de $20^{\circ} \mathrm{C}$. A sincronia da germinação é benéfica para a pesquisa e produção de mudas florestais partindo de sementes para otimizar o tempo e organizar o trabalho. Embora a entropia na germinação de sementes de Eucalyptus dunnii tenha sido alterada pela temperatura de 20 a $30^{\circ} \mathrm{C}$, a resposta é individualizada para cada espécie vegetal. Segundo Nassif e Perez (2000), para sementes de Pterogyne nitens Tul. (amendoim-docampo), valores favoráveis de entropia encontraram-se numa faixa de temperatura entre 18 e $30^{\circ} \mathrm{C}$ sem variações.

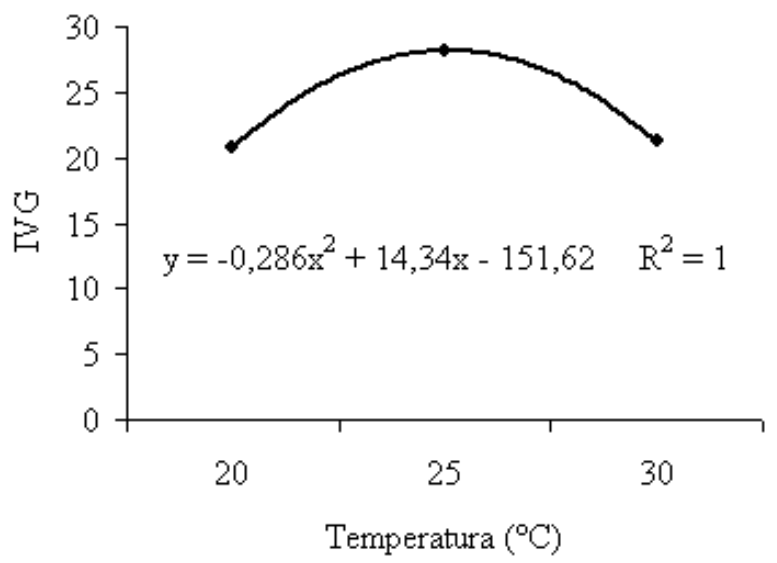

FIGURA 4: Índice de velocidade de germinação de sementes de Eucalyptus dunnii submetidas a diferentes temperaturas.

FIGURE 4: Germination speed index of Eucalyptus dunnii seeds submitted to different temperatures. 


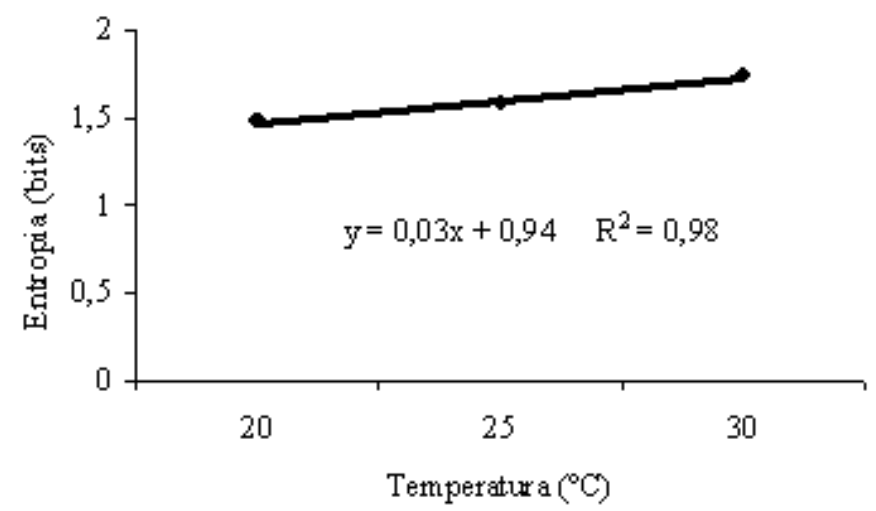

FIGURA 5: Entropia (bits) na germinação de sementes de Eucalyptus dunnii submetidas a diferentes temperaturas.

FIGURE 5: Entropy (bits) on the germination of Eucalyptus dunnii seeds submitted to different temperatures.

Analisando-se todas as variáveis em conjunto, verifica-se que a germinação é maior e mais sincronizada a $20^{\circ} \mathrm{C}$, embora seja mais rápida a $25^{\circ} \mathrm{C}$ em torno de um dia. A $30^{\circ} \mathrm{C}$ a germinação é menor e menos sincronizada, tornando essa temperatura menos adequada à germinação das sementes, embora não se caracterize como crítica à germinação. Os diferentes substratos não interferiram no percentual final de germinação em qualquer temperatura (Figura 1). Na temperatura de $20^{\circ} \mathrm{C}$ a areia demonstrou ser mais favorável ao menor tempo de germinação e maior IVG, assemelhando-se ao papel. A vermiculita foi considerada o substrato menos adequado para os parâmetros tempo de germinação e IVG nessa temperatura. Já a $25^{\circ} \mathrm{C}$, os três substratos proporcionaram resultados semelhantes.

\section{CONCLUSÕES}

O teste de germinação de sementes de Eucalyptus dunnii pode ser realizado com massa de $50 \mathrm{mg}$ de sementes puras da amostra.

Os substratos areia ou papel devem ser utilizados para o teste de germinação de Eucalyptus dunnii.

A temperatura de $20^{\circ} \mathrm{C}$ proporcionou melhor desempenho da população de sementes de Eucalyptus dunni no teste de germinação em laboratório.

\section{REFERÊNCIAS BIBLIOGRÁFICAS}

AMBIENTE BRASIL. Silvicultura do Eucalipto (Eucalyptus spp.). Disponível em: $<\underline{\text { http://www.ambientebrasil.com.br/composer.php3?base=./florestal/index.html\&conteudo=./florestal/eucalipto.html }>}$ Acesso em: 07 de julho de 2006.

ANDRADE, R. A.; MARTINS, A. B. G. Influence of the temperature in germination of seeds of jabuticaba tree. Revista Brasileira de Fruticultura, Jaboticabal, v. 25, n. 1, p. 197-198, abr., 2003.

BILIA, D. A. C.; BARBEDO, C. J.; MALUF, A. M. Germinação de diásporos de canela (Ocotea corymbosa (Meissn.) Mez - LAURACEAE) em função da temperatura, do substrato e da dormência. Revista Brasileira de Sementes, Brasília, v. 20, n. 1, p. 189-194, 1998.

BRACELPA. Área total reflorestada existente em 31/12/2004. Disponível em: <(http://www.bracelpa.org.br/br)> Acesso em: 07 de julho de 2006.

BRASIL. Ministério da Agricultura e Reforma Agrária. Regras para análise de sementes. Brasília-DF: Departamento Nacional de Produção Vegetal - SNA/DNPV/CLAV. 1992. 365 p.

CARVALHO, N. M.; NAKAGAWA, J. Sementes: Ciência, tecnologia e produção. Campinas: Fundação Cargill, 1988. $424 \mathrm{p}$.

EMBRAPA. Cultivo do Eucalipto: Importância socioeconômica e ambiental. Disponível em: $<$ http://sistemasdeproducao.cnptia.embrapa.br/FontesHTML/Eucalipto $>$ Acesso em: 07 de julho de 2006.

FERREIRA, E. M. et al. Determinação do tempo ótimo de enraizamento de miniestacas de clones de Eucalyptus spp. Revista Árvore, Viçosa, v. 28, n. 2, p. 183-187, mar./abr., 2004.

IOSSI, E. et al. Efeitos de substratos e temperaturas na germinação de sementes de tamareira-anã (Phoenix roebelenii O’Brian). Revista Brasileira de Sementes, Brasília, v. 25, n. 2, p. 63-69, dez. 2003. 
KÄMPF, A. N. Substratos. In: KÄMPF, A. N. Produção comercial de plantas ornamentais. Guaíba: Agropecuária, 2000. p. 45-72.

LORENZI, H. Arvores exóticas no Brasil: madeireiras, ornamentais e aromáticas. Nova Odessa: Instituto Plantarum, 2003. $368 \mathrm{p}$.

MACHADO, C. F. et al. Metodologia para a condução do teste de germinação de sementes de ipê-amarelo (Tabebuia serratifolia (Vahl) Nicholson). Revista Cerne, Lavras, v. 8, n. 2, p. 17-25, 2002.

NASSIF, S. M. L.; PEREZ, S. C. J. G. Efeito da temperatura na germinação de sementes de amendoim-do-campo (Pterogyne nitens Tul.), Revista Brasileira de Sementes, Brasília, v. 22, n. 1, p. 1-6, 2000.

OLIVEIRA, E. C.; PIÑA-RODRIGUES, F. C.; FIGLIOLIA, M. B. Propostas para a padronização de metodologias em análise de sementes florestais. Revista Brasileira de Sementes, Brasília, v.11, n. 1-3, p. 1-42, 1996.

PACHECO, M. V. et al. Efeito de temperaturas e substratos na germinação de sementes de Myracrodruon urundeuva Fr. All. (Anacardiaceae). Revista Árvore, Viçosa, v. 30, n. 3, p. 359-367, mai./jun., 2006.

PINÃ-RODRIGUES, F. C. M.; FIGLIOLIA, M. B.; PEIXOTO, M. C. Testes de qualidade. In: FERREIRA, A. G.; BORGHETTI, F. (Orgs.) Germinação: do básico ao aplicado. Porto Alegre: Artmed, 2004. p. 283-297.

SILVA, L. M. M.; RODRIGUES, T. J. D.; AGUIAR, I. B. Efeito da luz da temperatura na germinação de sementes de aroeira (Myracrodruon urundeuva Allemão). Revista Árvore, Viçosa, v. 26, n. 6, p. 691-697, nov./dez., 2002.

SOUSA, M. P. et al. Influência da temperatura na germinação de sementes de samaúma (Ceiba pentandra (Linn.) Gaertn. - Bombacaceaea). Revista Brasileira de Sementes, Brasília, v. 22, n. 1, p. 110-119, 2000.

TITON, M.; XAVIER, A.; OTONI, W. C. Dinâmica do enraizamento de microestacas e miniestacas de clones de Eucalyptus grandis. Revista Árvore, Viçosa, v. 26, n. 6, p. 665-673, nov./dez., 2002.

VARELA, V. P.; COSTA, S. S.; RAMOS, M. B. P. Influência da temperatura e do substrato na germinação de sementes de itaubarana (Acosmium nitens (Vog.) Yakovlev) - Leguminosae, Caesalpinoideae. Acta Amazonica, Manaus, v. 35, n. 1, p. 35-39, jan./mar., 2005. 